\title{
Clinical implications of irregular ADMET properties with levodopa and other antiparkinson's drugs
}

Livia Dézsi ${ }^{1}$ MD and László Vécsei ${ }^{1,2 *}$ MD, PhD, DSc, Member of the Hungarian Academy of Sciences.

${ }^{1}$ Department of Neurology, University of Szeged

${ }^{2}$ Neuroscience Research Group of the Hungarian Academy of Sciences

*Author for correspondence

1,2 Address:

H-6725 Szeged, Semmelweis u. 6, Hungary

Tel:+36 62545351

Fax:+36 62545597

vecsei@nepsy.szote.u-szeged.hu

dezsilivia@gmail.com

\begin{abstract}
Introduction: Parkinson's disease is neurodegenerative disorder characterized by the loss of striatal dopaminergic neurons. Besides the improvement of the dopaminergic loss, the treatment focuses on non-dopaminergic medication targeting motor and non-motor symptoms, and on the development of neuroprotective medication. A good knowledge of the properties of the compounds used is essential not only for those involved in pharmacological research, but also for those who treat Parkinson's disease patients, facing their still many unmet needs.

Areas covered: The review discusses the pharmacokinetic properties of levodopa, and factors influencing them, the pharmacodynamics of levodopa and approaches with the aim of improving this, covering some of the other antiparkinson medication available. Among the non-dopaminergic agents, it focuses on research on kynurenines. A literature search was made
\end{abstract}


in Pubmed for Parkinson's disease treatment, levodopa, levodopa absorption, levodopa pharmacokinetics, continuous dopaminergic stimulation, levodopa-carbidopa intra-intestinal gel therapy, dopamine agonists, monoamine oxidase-B inhibitors and kynurenines.

Expert opinion: Various factors can cause irregularities in the pharmacokinetics of levodopa, with interconnected consequences on its therapeutic effect. Its long-term use is associated with the development of motor complications; this is explained mostly by pharmacodynamic, but also by pharmacokinetic properties, the latter gaining in importance in the advanced stages of the disease.

\section{Introduction}

Parkinson's disease (PD) is the second most frequent neurodegenerative disorder following Alzheimer's disease. The incidence rises stepwise with increasing age, to 93.1 in 100,000 person years between 70 and 79 years of age [1]. PD is characterized by a progressive loss of dopaminergic cells in the substantia nigra (SN) pars compacta. The motor symptoms of the disease include tremor, rigidity, bradykinesia and postural instability. Nonmotor symptoms can manifest even in the early stages of the disease and have a great impact on the quality of life (see Table 1). The non-dopaminergic pathways also play a role in their occurence.

For decades, treatment has focused on correcting the dopaminergic loss and thereby alleviating the cardinal motor symptoms of the disease. There is growing interest in nondopaminergic medication that moderates the motor and non-motor symptoms and dyskinesias. In addition to symptomatic treatment, efforts are being made to develop putative neuroprotective medication capable of preventing the progression of the disease.

\section{$\underline{\text { Article highlights }}$}

- The characteristics of the pharmacokinetics of levodopa are a short $\mathrm{T}_{1 / 2}$, absorption through active transport in the small intestine and at the BBB, an extensive peripheral metabolism and renal elimination of the metabolites.

- The absorption of levodopa is influenced by delayed gastric emptying, competition for the absorption sites in the small bowel and infections occurring in the GI tract, such as SIBO and HP infection. 
- In the advanced stages of the disease, the fluctuating plasma dopamine levels can not be buffered by the decreasing number of functional dopaminergic neurons and dopaminergic stimulation becomes dependent on the plasma levodopa level.

- LCIG therapy provides more continuous absorption and consequently steadier levodopa blood levels, but has several limitations.

- As compared with levodopa, DAs have a longer $T_{1 / 2}$ and a more stable pharmacokinetic profile. Among DAs, the apomorphine pump, transdermal rotigotine and ER formulations are approaches through which to provide a more constant stimulation of the dopamine receptors.

Among non-dopaminergic medication, neuroactive kynurenines could provide a neuroprotective effect in patients with PD.

\section{Levodopa}

Since its introduction in the 1960s, in spite of the therapeutic challenge of the motor complications (MCs) that emerge in time, levodopa (LD) remains the best symptomatic treatment, and is the gold standard of the therapy of PD. A number of factors can cause irregularities in the absorption, distribution, metabolism, excretion and toxicity (ADMET) of LD, with consequences on the therapeutic effect. The introduction of LD was followed by the development of inhibitors of dopamine-metabolizing enzymes and dopamine receptor agonists in order to lower the risk of MCs and to provide better symptomatic control. Different formulations of LD, such as controlled or extended-release (ER) preparations and new approaches, such as levodopa-carbidopa intra-intestinal gel (LCIG) therapy, are also available.

\section{Pharmacokinetics of levodopa}

LD is a prodrug, a dopamine precursor. In order to exert its antiparkinsonian effects, several steps are needed, such as gastrointestinal (GI) absorption, passage across the bloodbrain barrier (BBB), neuronal uptake, enzymatic conversion to dopamine through an aromatic amino acid decarboxylase (AADC), and synaptic release. This chapter outlines the characteristics of the pharmacokinetics of LD and the factors on which it depends. Long-term therapy causes no substantial changes in the peripheral pharmacokinetics of LD, but leads to changes in the central pharmacokinetics and pharmacodynamics responsible for the development of LD-related MCs. Accordingly, the peripheral pharmacokinetics becomes of greater importance in more advanced stages of disease [2]. 


\subsection{Absorption of levodopa and factors influencing it}

LD itself is unable to cross the BBB. It is actively transported through the intestinal wall and the BBB by an amino acid transporter for large neutral amino acids. When coadministered with an AADC, it is rapidly absorbed, with a bioavailability of $84-99 \%$ for oral administration [3]. The rate of absorption depends on the gastric $\mathrm{pH}$, on the rate of gastric emptying, and on the time during which the drug is exposed to the gastric acid and the intestinal flora containing the degrading enzymes. Absorption may be impaired by hyperacidity of the gastric juice, delayed gastric emptying and competition for absorption sites in the small intestine. These factors are also interrelated. In this respect, excessive gastric acidity can delay gastric emptying. On the other hand, excessive neutralization of the gastric acidity leads to the incomplete dissolution and absorption of LD tablets [2, 4].

1.1.1. Delayed gastric emptying (DGE): Low gastric motility and constipation are characteristic non-motor symptoms of PD and lead to DGE [5], especially in PD patients with motor fluctuations [6]. The stimulation of gastric dopamine receptors also depresses the gastric motility. DGE triggers an extensive metabolism that results in less LD being available for absorption. Gastric emptying contributes to a varying plasma LD level and bioavailability, which influences the delivery of LD to the brain and ultimately the motor response [7]. It has been shown that erratic absorption contributes to pulsatile stimulation of the striatal dopaminergic receptors, which results in time in dyskinesias and MCs. DGE delays and blunts the peak LD concentration $\left(\mathrm{C}_{\max }\right)$, leading to a delay or failure of the clinical response. $\mathrm{A}$ delayed-on phenomenon emerges, or in more severe cases no-on occurs, when no symptomatic effect can be seen, or the unpredictable off phenomenon [2,6]. DGE and slow intestinal motility favor the occurrence of local infections, which can further diminish the absorption and influence the clinical response [8].

The efficiency of gastric emptying can be improved by the withdrawal of anticholinergic drugs and the relief of constipation with a high-fiber and fruit diet, oil or lactulose [2]. Domperidon can be added to LD preparations in order to minimize this problem. The absorption of LD is better from orally disintegrable tablets, such as dispersible, methylester or ethyl-ester preparations [9]. The $C_{\max }$ is then earlier reached and the clinical effect more predictable and reliable $[10,11]$. An intra-intestinal preparation avoids the unsteady absorption seen with oral formulations. 
Table 1. Non-motor symptoms of PD

\begin{tabular}{|c|c|}
\hline $\begin{array}{l}\text { Neuropsychiatric symptoms } \\
\text { - depression } \\
\text { - } \text { psychosis } \\
\text { - } \text { anxiety } \\
\text { - fatigue } \\
\text { - impulse control disorder } \\
\text { - cognitive impairment } \\
\text { - dementia }\end{array}$ & $\begin{array}{l}\text { Autonomic symptoms } \\
\text { - } \quad \text { drooling } \\
\text { - } \text { increased sweating } \\
\text { - } \text { gastrointestinal dysfunction } \\
\text { - } \quad \text { bladder dysfunction } \\
\text { - } \quad \text { orthostatic hypotension } \\
\text { - } \quad \text { sexual dysfunction }\end{array}$ \\
\hline $\begin{array}{ll}\text { Sleep disorder } \\
\text { - } \\
\text { - } & \text { REM sleep behavior disorder } \\
\text { - } & \text { restless legs syndrome } \\
\text { - } & \text { insomnia } \\
\text { - } & \text { excessive daytome sleepiness }\end{array}$ & $\begin{array}{cl}\text { Sensory symptoms } & \text { anosmia } \\
\text { - } & \text { pain } \\
\text { - } & \text { paresthesia }\end{array}$ \\
\hline
\end{tabular}

REM: rapid eye movement

1.1.2. Infectious agents: It has been demonstrated, that infection with Helicobacter pylori (HP), or gastritis with some other etiology, can diminish the absorption of LD and influence motor fluctuations. In some studies, HP infection was found to be more prevalent in PD patients than in healthy controls $[12,13]$, though this finding was not verified in other studies [14]. HP infection was associated with the no-on and wearing-off phenomena and a higher prevalence of unpredictable motor fluctuations; eradication of HP infection improved the absorption of LD $[12,13]$. In a more recent study investigating the effect of HP infection on the clinical response to LD, no higher prevalence of motor fluctuations was found with HP infection. $27 \%$ of the 75 PD patients included were HP infected. Wearing off and sleep disturbance were significantly less common among them; no significant difference in the LD equivalent doses was seen. Authors concluded that the less symptom fluctuation might be due to an altered absorption of LD in the HP infected patients [15]. There is a connection between small intestinal bacterial overgrowth (SIBO) and HP infection, because HP causes atrophic gastritis with hypoacidity, predisposing to SIBO [16]. The contribution of SIBO to the pathophysiology of motor fluctuations was investigated in a study. SIBO was found significantly higher in PD patients compared to controls, but HP infection was not more prevalent. Patients with such infectious conditions displayed a significantly longer gastric emptying time, a higher prevalence of unpredictable motor fluctuations, a longer off time, and more delayed-on and no-on. Eradication of the infection improved the motor fluctuations without affecting the pharmacokinetics of LD [14]. 
1.1.3. Competition for absorption sites: Absorption depends on protein intake, as proteins act as competitive inhibitors of the active carrier through the intestinal wall and the BBB [17]. Even though they avoid high-protein meals, many patients do not experience the expected on mobility. According to some authors, this might be influenced by the presumption that more LD is required when patients are physically active [2]. In order to minimize the effects of proteins on its absorption, the intake of LD should be recommended before meals or with a low-protein intake [18].

1.1.4. Nicotine: The pharmacokinetics of LD is influenced by nicotine. Nicotine used as a patch or gum can improve the symptoms of PD, as revealed for nicotine gum in juvenile PD patients [19]. In mouse models, nicotine improved LD-related dyskinesias [20], and the same was found for nicotinic receptor agonists in a monkey model [21]. Clinical studies of the effects of nicotine on PD symptoms have led to contradictory conclusions. In a relatively recent study, some motor worsening was seen after nicotine was administered with or without LD, irrespective of LD intake [22]. A subthreshold stimulation of the presynaptic D2 receptors by a low nicotine concentration was considered to be responsible for the transient motor worsening. A high-dose nicotine patch and chronic intravenous nicotine treatment followed by patch use improved the motor and the motor and cognitive symptoms of PD patients, respectively. In the intravenous approach followed by patch administration, the response lasted even after cessation of the therapy $[23,24]$. In an earlier study, nicotine patch was not effective [25]. In healthy subjects, nicotine did not influence the gastric emptying, while in those smoking high-dose nicotine cigarettes the gastric emptying was delayed relative to that in those smoking low-dose nicotine cigarettes. In a study of the effects of nicotine on the pharmacokinetics of $\mathrm{LD}, \mathrm{C}_{\max }$ and the area under the plasma concentration-time curve from 0 to 4 hours for LD did not differ significantly in patients using a nicotine patch and controls. The difference in the plasma concentration of LD between $\mathrm{C}_{\max }$ and $30 \mathrm{~min}$ after $\mathrm{C}_{\max }$ was reduced in the nicotine patch group as compared with the controls. The mean plasma LD concentration was significantly lower in the nicotine patch group. The plasma LD concentration curve was smoother during nicotine treatment. No significant differences in gastric emptying were seen between the two groups as measured by the ${ }^{13} \mathrm{CO}_{2}$ breath test. In cultures on Caco- 2 cells, nicotine reduced the amount of permeated LD, by as much as $25 \%$. Nicotine stimulates endogenous dopaminergic synthesis and as a result may modulate dopaminergic neurotransmission [26].

\subsection{Distribution of levodopa}


The plasma LD concentration peaks at $0.5-2 \mathrm{~h}$ after an oral dose. The plasma half-life $\left(T_{1 / 2}\right)$ is short, at 36-96 min [17]. The $C_{\max }$ and $T_{1 / 2}$ of LD influence the therapeutic effect, more markedly in the advanced stages of the disease. According to a study a long term therapy increases $\mathrm{C}_{\max }$ and decreases $\mathrm{T}_{1 / 2}$ [27]. Taking LD after a meal can extend the duration of its efficacy. When LD is taken after a meal $\mathrm{C}_{\max }$ is decreased and $\mathrm{T}_{1 / 2}$ is increased as compared with taking it before meals; therefore, taking LD after a meal might extend the effective time and decrease the dyskinesia [28]. LD is distributed to most tissues. Less reaches the cerebral circulation in an unchanged form and only about $1 \%$ of the ingested drug reaches the central nervous system, due to its extensive peripheral metabolism [29]. Adding a peripheral AADC (carbidopa or benserazide) considerably elevates the level of LD entering the CNS and controls side-effects due to peripheral decarboxylation, such as vomiting or nausea. All LD compounds, including oral and intraintestinal formulations, therefore contain an AADC inhibitor.

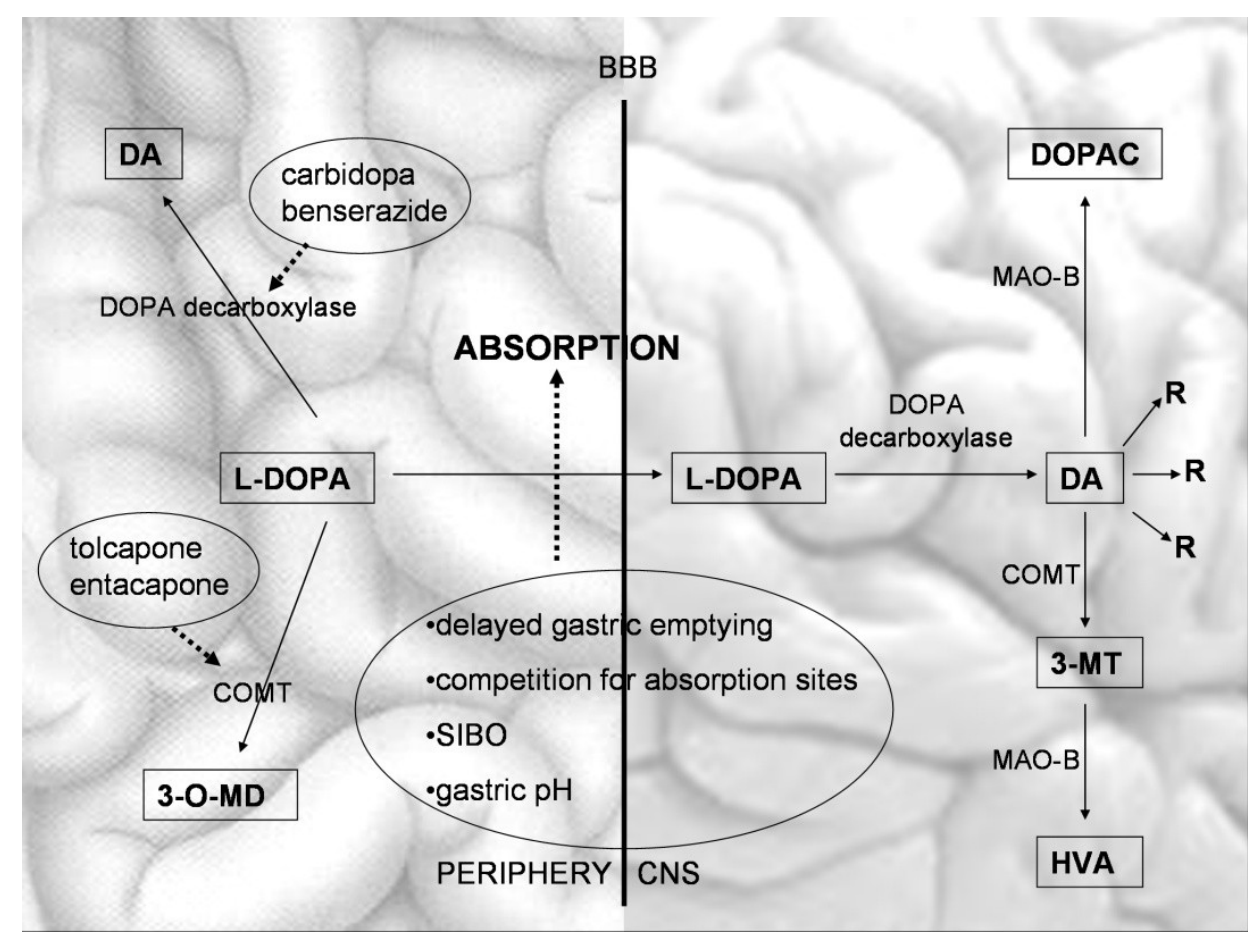

Figure 1: Absorption and metabolism of levodopa.

BBB: blood-brain barrier, CNS: central nervous system, COMT: catechol-O-methyl transferase, DA: dopamine, DOPAC: 3,4-dihydroxyphenylacetic acid, HVA: homovanillic acid, L-DOPA: levodopa, MAO-B: monoamine oxidase B, 3-MT: 3-methoxytyramine, 3-OMD: 3-O-methyldopa, R: dopamine receptors, SIBO: small intestinal bacterial overgrowth. Discontinuous arrow: inhibition

\subsection{Metabolism of levodopa}


The metabolism of LD occurs in the GI tract and in the brain (Figure 1). The enzymatic modification of LD is a result of the action of dopa- or AADC, monoamine oxidase $\mathrm{B}$ (MAO-B) and catechol-O-methyl transferase (COMT). In the periphery, the extracerebral AADC breaks down about $95 \%$ of the total LD to dopamine. The drug is also decarboxylated during the first passage through the liver. A smaller amount undergoes methylation to 3-Omethyldopa in the GI tract, due to COMT activity. When it is administered alone, the main metabolic route is decarboxylation, whereas when it is administered with an AADC inhibitor, the main metabolic pathway is the formation of 3-O-methyldopa. Methyldopa has a 10 times longer half-life than that of LD and it exhibits a high plasma concentration after chronic treatment [30]. Although it can theoretically compete with LD for active transport sites across the BBB, it does not alter the transport of LD [31].

The result of its peripheral metabolism is a lower level of LD entering the brain and an increased blood dopamine level. Dopamine is a catecholamine that acts on alpha and betaadrenergic receptors and is responsible for the toxic effects of LD. LD crosses the BBB, and is taken up by the dopaminergic neurons, where it is decarboxylated to pharmacologically active dopamine in the presynaptic terminals of the basal ganglia. The addition of an enzyme inhibitor reduces its peripheral metabolism and improves its bioavailability. Among the peripheral decarboxylase inhibitors, carbidopa has a variable and slow absorption as compared with that of $\mathrm{LD}$ and a longer $\mathrm{T}_{1 / 2}$ in consequence of which its plasma concentration stabilizes later. It is presumed to have a different mechanism of transport.

The addition of COMT inhibitors to LD increases the bioavailability of LD, and extends its $T_{1 / 2}$ [28], but does not increase the time to $C_{\max }$, nor the $C_{\max }$ [32]. According to other studies $\mathrm{C}_{\max }$ was significantly higher after the addition of a COMT inhibitor [33].

As a result, more LD is delivered across the BBB over a longer time and more LD enters the brain and reaches the striatum, where it is converted to dopamine. Preclinical trials showed less dyskinesia and fewer motor fluctuations following the entacapone-LD combination than after LD alone [34]. Clinical trials supported these observations (FIRST STEP study) [35], but did not prove that the LD/carbidopa/entacapone combination can delay dyskinesia as compared with LD/carbidopa; in fact the opposite was proven, that dyskinesias developed earlier and more with addition of entacapone (STRIDE-PD study) [36]. The COMT inhibitors tolcapone and entacapone are recommended in clinical practice for patients who exhibit the wearing-off phenomenon. The side-effects of COMT inhibitors include diarrhea, signs of excessive dopaminergic stimulation, and hepatic necrosis for tolcapone [37]. Though not substantial, some changes in pharmacokinetics can be seen in association 
with long-standing LD therapy. There may be an accelerated metabolism due to enzyme induction, a decrease in the $\mathrm{T}_{1 / 2}$ of $\mathrm{LD}$ and an increased $\mathrm{C}_{\max }$ [28].

\subsection{Elimination of levodopa}

There are several dozen metabolites, but the main urinary excretion products are 3-4dihydroxy phenylacetic acid (DOPAC) and 3-methoxy-4-hydroxy phenylacetic acid (homovanillic acid, HVA). These account for $50 \%$ of the administered dose. HVA alone accounts for $13-42 \%$ of the ingested LD dose [29]. As much as $80 \%$ of a radioactively labeled dose is excreted in the urine and recovered within $24 \mathrm{~h}$. Only small amounts are excreted through the feces. In time, after long-standing LD therapy, the amounts of DOPAC and HVA excreted increase, presumably due to a depletion of the methyl donors needed for the metabolism by COMT [31].

\subsection{Toxicity of levodopa}

The side-effects of LD (Table 2) [38, 39] are usually reversible when the dose is decreased or the drug is withdrawn, but there have been several reported cases of toxicity and even fatality due to LD overdoses. No data are available concerning the mutagenicity of LD. Carcinogenicity has not been proved, but there have been concerns regarding the activation of melanomas, though these have not been proved either. As to teratogenicity, it has been demonstrated in rabbits that LD causes visceral and skeletal malformations in the offspring. No relevant data are available on humans [31, 40].

The most troublesome feature, with a negative impact on the quality of life of the patient, are the MCs that develop in time, such as choreiform and/or dystonic movements, variable in morphology, involving eyes, head, trunk or extremities. Their frequency increases, as the drug administration continues and are related to the doses administered. They occur in up to $10 \%$ of the patients per year with each year of therapy, or in about $50 \%$ of the patients after 5 years of therapy and in almost $100 \%$ after 10 years [2, 41]. Dyskinesias have been reported to have an incidence ranging from $8 \%$ to $64 \%$ of the patients after $4-6$ years of therapy [42].

Sudden LD withdrawal can lead to a neuroleptic malignant-like syndrome with akinesia, rigidity, fever and autonomic disturbances. Drug interactions (Table 3) can influence the metabolism of LD and thereby its side-effects. Long-standing treatment interferes with the metabolism of vitamin B12, folate and homocysteine, leading to an increase in homocysteine levels and deficiencies of vitamin B12 and folate [43].

\subsubsection{Concerns of LD toxicity}


A few years after the discovery of LD and its introduction in clinical practice, a debate arose concerning its toxicity $[44,45]$. The concerns were based on the development of MCs after some years of treatment and the presumption that LD might accelerate neuronal degeneration through free radicals generated by its oxidative metabolism. There are increased $\mathrm{Fe}^{++}$, decreased glutathione and increased malondialdehyde levels and a decreased mitochondrial complex I activity in the SN of PD patients, suggesting that free radicals play a role in the pathological processes and apoptosis of midbrain dopaminergic neurons $[44,46]$. $\mathrm{H}_{2} \mathrm{O}_{2}$, the precursor of the toxic hydroxyl radical, is a product of dopamine metabolization via MAO. In the surviving neurons there is an increased rate of metabolism, with further free radical formation. LD was therefore proposed as second-line therapy. In the ELLDOPA trial, which compared different doses of LD with placebo in patients with early $\mathrm{PD}$, the results suggested that it is not toxic, but may in fact be neuroprotective [47], and that it does not accelerate the progression of PD and can be recommended at an early stage of the disease [44, 48-50].

\section{Pharmacodynamics of LD and clinical implications}

The antiparkinsonian effect of LD relies on the synthesis of dopamine and its interaction with the dopamine receptors. The efficacy of LD varies due to factors that influence its absorption, distribution and metabolism and the subsequent fluctuations in its plasma level. For the first months or years, of therapy, the honeymoon period, LD provides a stable improvement. Later, the effect wears off a few hours following intake, with resultant periods of on and off fluctuations in relation to the peripheral LD concentration. PD patients can also experience choreiform movements occurring typically at peak blood LD levels (peak-dose dyskinesia). Less characteristic, dyskinesia can also occur at decreasing blood LD levels (end-of-dose dyskinesia). The therapeutic window of LD narrows in time and MCs are more likely to occur seemingly unrelated to medication intake.

Under physiological conditions, dopaminergic neurons store and regulate the release of dopamine, and the dopaminergic receptors are exposed to relatively constant levels of dopamine [51]. In the PD patient, oral substitution therapy is considered to be one of the major factors contributing to the pulsatile stimulation of the receptors, due to the short $T_{1 / 2}$ [52]. As the disease progresses, the number of striatal neurons decreases and there are fewer neurons capable to buffer a short-acting dopaminergic agent. The loss of striatal dopaminergic neurons and the dysregulation of the events following the receptor binding cause the 
dependence of the striatal dopamine concentration and of dopaminergic stimulation on the plasma LD level, which in turn is dependent on the LD intake [53].

Exposure of dopamine receptors to fluctuating neurotransmitter levels causes discontinuous or pulsatile stimulation, which is presumed to be responsible for the MCs [54]. It has been postulated that such pulsatile stimulation causes hypersensitivity of the striatal dopamine receptors. It induces molecular changes in the striatal neurons and neurophysiological changes in the outputs which underlie motor fluctuations and dyskinesias [55]. It has been proposed that previous exposure to LD, i.e. LD priming increases the susceptibility to the development of dyskinesias [52] and in this respect the pulsatile activation of D2 dopamine receptors is considered to be most strongly involved [56]. Continuous stimulation of the dopaminergic receptors has been presumed to cause less fluctuation and dyskinesia [57].

The continuous dopaminergic stimulation (CDS) hypothesis explained the development of MCs as a consequence of a short LD $\mathrm{T}_{1 / 2}$. This theory is falling out of favor, because studies with longer-acting dopaminergic preparations showed no significant differences in the occurrence of dyskinesias [58] and could not explain their development based on the short $T_{1 / 2}$ of the preparations used. In animal models, a continuously administered short-acting dopamine agonist (apomorphine) caused less dyskinesia [59]. This means that a short-acting dopaminergic medication, which according to the CDS hypothesis would cause more dyskinesias, if delivered continuously, lowers the risk of MCs. The CDS has recently been replaces by the continuous dopaminergic delivery (CDD) concept, CDD having the goal of reducing MCs by delivering a drug in a constant manner, regardless of its $\mathrm{T}_{1 / 2}[60]$.

Several approaches aiming to provide a more continuous plasma levodopa level and thereby to reduce motor complications have been developed. In everyday clinical use, in order to treat motor complications LD doses can be divided throughout the day, ER formulations are available, or a dopamine-metabolizing enzyme inhibitor, such as a COMT inhibitor can be added. Amantadine has also proved efficacy in the treatment of dyskinesias and new delivery technologies, such as the LCIG therapy and the apomorphine subcutaneous pump are now available.

Table 2. Levodopa side-effects 


\begin{tabular}{|c|c|}
\hline $\begin{array}{l}\text { Cardiac } \\
\text { - } \text { orthostatic hypotension } \\
\text { - arrhythmia due to the beta-adrenergic effect } \\
\text { of dopamine and other levodopa metabolites. }\end{array}$ & $\begin{array}{l}\text { Central nervous system } \\
\text { - } \text { mental changes } \\
\text { - } \text { depression } \\
\text { - } \text { paphoria } \\
\text { - } \text { psychosis, hallucination, delusion } \\
\text { - confusion } \\
\text { - insomnia, nightmares } \\
\text { - } \text { genxiety, agitation } \\
\text { - tiredness } \\
\text { - clumsiness } \\
\text { - } \text { blurred vision }\end{array}$ \\
\hline $\begin{array}{ll}\text { Gastrointestinal } \\
\text { - } & \text { anorexia } \\
\text { - } & \text { nausea } \\
\text { - } & \text { vomiting } \\
\text { - } & \text { abdominal pain } \\
\text { - } & \text { constipation } \\
& \text { bleeding and perforation of peptic ulcers }\end{array}$ & $\begin{array}{l}\text { Hematologic* } \\
\text { - hemolytic anemia } \\
\text { - } \text { agranulocytosis } \\
\text { elevation of } \\
\text { - blood urea nitrogen } \\
\text { - SGOT, SGPT, LDH, bilirubin, alkaline } \\
\text { phosphatase, protein-bound iodine, } \\
\text { decreased prolactin } \\
\text { - it acts on the adenohypophysis and stimulates } \\
\quad \text { the release of prolactin inhibitory factor. }\end{array}$ \\
\hline $\begin{array}{l}\text { Urinary } \\
\text { - Loss of bladder control } \\
\text { - Difficult urination }\end{array}$ & $\begin{array}{l}\text { Dermatological } \\
\text { - Skin rash } \\
\text { - } \quad \text { Swelling of feet or lower legs }\end{array}$ \\
\hline
\end{tabular}

Several of the listed side-effects are meanwhile non-motor symptoms of PD, for example constipation, depression, anxiety or hypotension.

It is necessary to carry out periodic evaluations of hepatic, hematological and renal functions in patients taking LD

1. LCIG treatment avoids the variability of plasma levels due to impaired gastric emptying and the breakdown of LD by the gastric juice. Due to the by-passing of the gastric emptying, there is a significant smoothing of the plasma LD level and a reduction of the response fluctuations [2]. In a study on 19 patients [61], the full plasma concentration versus time profiles of LD, carbidopa and 3-O-methyldopa were evaluated. LD rapidly achieved therapeutic plasma levels, which were constant during the infusion. A small peak was observed during the first $3 \mathrm{~h}$ of infusion after the morning dose, and another due to the slower absorption of carbidopa. Meals also caused small fluctuations in the plasma LD level, which were 8.3 and 3.7-fold less than those with immediate release (IR) and ER preparations, respectively. After the infusion, the plasma LD level decreased rapidly. The absolute LCIG bioavailability was estimated to be $88 \%$ in one analysis, which is comparable to that following oral administration [62].

LCIG treatment is delivered via a percutaneous endoscopic jejunostomy and a portable infusion pump. The pump is easy to use, but there is a considerable demand for caregiver 
burden, because patients in an advanced disease stage can exhibit severe motor fluctuations, off periods and dyskinesias, when they are unable to adjust the parameters of the pump [63]. Technical problems can occur that are related to the jejunostomy tube, but more troublesome ones can arise from the surgical procedure, such as secretion, infections and inflammation at the site of the PEG/PEJ tube [64]. Tolerance has been revealed in experimental studies [65]. An axonal polyneuropathy, often associated with vitamin B deficiency can occur with this procedure, which may be explained by the impaired absorption of vitamins and the interference of LD with the vitamin B12 metabolism [66, 67]. A 24 h delivery has the risk of LD toxicity and psychosis, because of which most patients are advised to stop the pump overnight. In a large open label trial, no patients were reported to develop visual hallucinations or psychosis [68]. The high cost limits wide-scale use of this therapy.

Table 3. Drug interactions

\begin{tabular}{|l|l|l|}
\hline Drug & Effect on LD & Result of interaction \\
\hline pyridoxine & enhances peripheral metabolism of LD & $\begin{array}{l}\text { increases the LD side-effects due to } \\
\text { excessive peripheral decarboxylation }\end{array}$ \\
\hline $\begin{array}{l}\text { dopamine receptor } \\
\text { antagonists }\end{array}$ & block the symptomatic effect of LD & decrease the symptomatic effect of LD \\
\hline nonspecific MAOIs & $\begin{array}{l}\text { unpredictably interfere with } \\
\text { catecholamine inactivation } \\
\text { augment the central effects of levodopa }\end{array}$ & hypertensive crisis and hyperpyrexia \\
\hline
\end{tabular}




\begin{tabular}{|c|c|c|}
\hline anticholinergics & slow gastric emptying & can reduce absorption of levodopa. \\
\hline $\begin{array}{l}\text { amantadine } \\
\text { AADC inhibitors } \\
\text { atropine } \\
\text { amphetamine. }\end{array}$ & various mechanisms & enhance the LD effect \\
\hline antihypertensives & reduce blood pressure & increase hypotension \\
\hline $\begin{array}{l}\text { anesthetics } \\
\text { - cyclopropane } \\
\text { - halothane } \\
\text { sympathomimetics } \\
\text { - epinephrine } \\
\text { - isoprenaline }\end{array}$ & various mechanisms & $\begin{array}{l}\text { worsen cardiac side-effects of LD, such as } \\
\text { arrhythmias }\end{array}$ \\
\hline propranolol & beta-adrenergic blocker & $\begin{array}{l}\text { enhances LD action on tremor } \\
\text { diminishes cardiac side-effects of LD }\end{array}$ \\
\hline
\end{tabular}

LD: levodopa, MAOIs: monoamine oxidase inhibitors, AADC: amino acid decarboxylase

2. ER formulations are another option through which to provide more continuous LD plasma levels. The ER formulations pose the same long-term dyskinesia risk as the standard formulation, and no superiority in controlling motor fluctuations [17]. Their absorption is erratic, and the plasma levels are unpredictable, which ultimately results in dose failures and a delay in clinical benefit [69].

An investigational ER carbidopa-LD (CD-LD) formulation (IPX066) is currently undergoing a phase III clinical trial. This tablet contains CD-LD microbeads that dissolve at different rates in the small intestine. The results indicate rapid absorption, with an onset of effect similar to that for the IR formulation, more sustained therapeutic plasma levels and a longer duration of clinical benefit [70]. The initial absorption rate is similar to that of the IR formulation. The plasma LD concentration is more sustained, remaining above $50 \%$ of $\mathrm{C}_{\max }$ for $4 \mathrm{~h}$ with IPX066 as compared with $1.4 \mathrm{~h}$ for IR. The plasma LD concentration fluctuation index evaluated on day 8 was more than $50 \%$ lower and the mean $\mathrm{C}_{\max } / \mathrm{C}_{\min } \mathrm{LD}$ ratio was more than 7-fold lower with IPX066 than with IR [71]. In a randomized, 13-week, blinded III study of 393 patients, IPX066 reduced the off time by an average of $1.17 \mathrm{~h}$ more than IR [72]. Although LD from IPX066 is 74.5\% bioavailable, patients needed a higher total daily dose in the IPX066 period relative to the IR period. The LD dose accumulates and there might be a risk of MCs at high doses [73]. However, since this high dose is delivered in a continuous form, maintaining a steady-state plasma concentration, it is conceptually different from a high dose given in a pulsatile manner. Theoretically, therefore there is no higher risk of dyskinesia and motor fluctuations and the reduction in dyskinesia is an effect on the central therapeutic window $[74,75]$. 
3. Intravenous LD infusion is not appropriate for chronic treatment, though it can reduce severity and incidence of dyskinesias, whereas the transdermal and transnasal routes of delivery are under investigation, but have not yet reached the market [17].

\section{Other dopaminergic medication}

\section{MAO-B inhibitors and their effects on the metabolism and efficacy of $L D$}

Selegiline and rasagiline are selective irreversible MAO-B inhibitors [76] that reduce dopamine breakdown, improve the dopamine deficiency symptoms and potentiate the effect of LD. The presumed neuroprotective effect has not been proved so far [77]. Due to loss the of selectivity for MAO-B at higher doses, at which inhibition of MAO-A can also occur, there is a risk of tyramine-induced hypertension, i.e. the cheese effect.

1.1.Selegiline has an extensive first-pass metabolism to amphetamine metabolites. Its oral bioavailability is about $25 \%$ in mice [78] and $10 \%$ in humans [79]. Two-thirds of the metabolite recovered from the urine is (R)-metamphetamine, formed by N-depropargylation. Other metabolites are desalkylated ones, further converted by para-hydroxylation and excreted as conjugates, and the recently described selegiline-N-oxide. Some are pharmacologically active and are responsible for the psychomotor stimulant and cardiovascular side-effects. The orally-disintegrating (ODT) form overcomes this pharmacokinetic problem. It has an improved bioavailability, allows a dose reduction and results in lower exposure to amphetamine metabolites. About $30 \%$ is absorbed in the mouth, while further absorption occurs in the GI tract, leading to a higher AUC value. There are no significant differences in AUC and $\mathrm{C}_{\max }$ for the conventional and the ODT formulation. Unfortunately, the improved pharmacokinetic profile is not accompanied by a significant clinical improvement and the efficacy and safety profiles are comparable to those of the conventional formulation. The transdermal formulation is used for the treatment of major depression [80].

1.2.Rasagiline is a second-generation propargylamine pharmacophore, that breaks down dopamine to DOPAC and HVA and acts in the deamination of beta-phenylethylamine which stimulates the release of dopamine and inhibits the neuronal reuptake of dopamine. The result is an elevation of the dopamine concentration in the synaptic cleft. Its bioavailability is $36 \%$. The dose linearity and proportionality for $\mathrm{C}_{\max }$ and AUC are consistent. A high-lipid meal reduced $\mathrm{C}_{\max }$ and AUC. Plasma protein binding is $60-70 \%$. Its hepatic biotransformation is extensive, but the metabolites are inactive and no extrahepatic clearance has been found. 
There are increases in $\mathrm{C}_{\max }$ and $\mathrm{AUC}$ in patients with hepatic failure, and it should therefore not be administered to those patients [81]. The mean $T_{1 / 2}$ is 1.34 hours, but this does not correlate with the symptomatic effect, because it irreversibly blocks MAO-B and the restoration of MAO-B activity depends on the regeneration of the enzyme, which was shown in a PET study to be around 40 days [82].

Rasagiline interacts with the CYP450 system. Administration of a CYP1A2 inhibitor such as ciprofloxacine, cimetidine or fluvoxamine increases the AUC of rasagiline, while CYP1A2 inducers, such as omeprazole, may reduce it. When added to LD, it may increase dyskinesias, but the difference is not significant. Patients receiving an oral challenge with tyramine in the TEMPO and PRESTO studies did not exhibit any significant increase of blood pressure [83]. Co-administration with agents enhancing serotonin levels, such as SSRI, SNRI, cyclic antidepressants or serotoninergic opioids, raises the concern of a risk of inducing the serotonin-like syndrome, and should therefore be avoided, though this risk could not be confirmed for antidepressants co-administered with rasagiline [84]. A meta-analysis based on the Medline and the Cochrane Library database demonstrated that rasagiline reduces motor scores in early PD, and reduces the off-time when added to LD in more advanced patients. The neuroprotective effect could not be proved in the delayed-start studies [85].

\section{Dopamine agonists}

Dopamine agonists (DAs) can be used as monotherapy in early PD, or as an add-to LD in advanced disease. There are two categories of these drugs: ergot-derived which act on D2 and D1 dopamine receptors and on some serotonin and adrenergic receptors and the nonergot-derived compounds, such as pramipexole and ropinirole, which act on D3 and D2 receptors. DAs directly stimulate the intact postsynaptic receptors in the striatum. There is no need for metabolic transformation for these drugs to gain effectiveness. They have a longer $\mathrm{T}_{1 / 2}$ than that of LD (6 and 8 hours for ropinirole and pramipexole, respectively) and provide a more prolonged stimulation of the receptors than I $n$ the case of LD. Another advantage is their selectivity to certain dopaminergic receptors, whereas LD stimulates all subtypes. DAs reduce LD metabolism and the generation of free radicals, and might therefore be neuroprotective [86]. Their effects on the non-motor symptoms of PD, such as depression, have also been shown [63].

The DAs offer a good antiparkinsonian effect and a lower risk of MCs, but several troublesome non-motor side-effects can occur, such as nausea, orthostatic hypotension, sleep attacks, REM sleep disorder, psychosis and impulse-control disorder [87]. As compared with 
LD, DAs cause less dyskinesia, but when used as monotherapy, relative to placebo they have consistently been associated with more dyskinesia (5-10\%) [52, 88]. In some studies, dyskinesia was also seen in the placebo groups, suggesting that other factors, not related to the DAs can contribute to their development. Pramipexole treatment increased LD-induceddyskinesia (LID) and its severity and duration and it is therefore presumed that the effect on LD is more than a simple additive effect [89]. In one study pramipexole-receiving patients displayed a slightly higher incidence of dyskinesia than that in the rotigotine group and both with a higher incidence in comparison with placebo (15\% and $12 \%$ vs $3 \%)$ [90]. The on time with no troublesome dyskinesias was significantly higher in the active treatment groups and no differences between pramipexole and rotigotine were observed. There is no evidence that pramipexole-related dyskinesias might be dose-dependent. No differences were found between the dyskinesia rates caused by ergot-derived and non-ergot DAs [91].

In order to provide a more continuous stimulation of the dopaminergic neurons, three approaches are available in this class of medication: the apomorphine pump, transdermal administration for rotigotine and ER formulations. The latter are available for both ropinirole and pramipexole. There is better compliance for ER preparations administered once daily [63]. The ER formulations provide a prolonged $\mathrm{T}_{1 / 2}$ and steadier plasma levels. In comparison with the IR formulation $\mathrm{C}_{\max }$ and $\mathrm{C}_{\min }$ and $\mathrm{AUC}$ for the same daily dose were equivalent [92]. Clinical trials revealed only the non-inferiority of pramipexole ER as compared to IR formulations; ER preparations did not cause higher rates of dyskinesia [93].

2.1. The apomorphine pump. Apomorphine is a water-soluble DA that is active on D1 and D2 receptors. It can be used as a subcutaneous injection delivered by a pen injector for acute treatment in the off periods, or as a continuous subcutaneous infusion. The onset of action is rapid: $5-15 \mathrm{~min}$. $\mathrm{T}_{1 / 2}$ is $40 \mathrm{~min}$. The effect is seen between 40 and $90 \mathrm{~min}$. The characteristic side-effect is nausea, and therefore an antiemetic such as trimethobenzamide or domperidone is recommended before treatment and can be slowly tapered off. Several studies have shown efficacy of subcutaneous apomorphine therapy. There are few interferences with other antiparkinson medication. Long-term therapy does not cause any delay in the onset of action, and there is no need for dose changes during therapy [94].

Apomorphine has been also tried in a sublingual form [95]. Subcutaneous infusion needs pretreatment with an antiemetic. As monotherapy, high doses would be needed, but are usually not tolerated. Oral LD supplementation is therefore needed, which modifies the continuous receptor stimulation effect of apomorphine infusion through a pulsatile stimulation effect. Other side-effects of apomorphine include subcutaneous nodules (70\%), somnolence 
(10\%), renal impairment, orthostatic hypotension, impulse control disorder and psychosis [64].

2.2. Rotigotine is a non-ergot-derived DA with activity on dopamine D1 through D5 receptors, and in particular on D3 receptors, as well as on adrenergic and serotoninergic sites. It has a convenient once-daily administration. It is contained in a silicone-based matrix for transdermal delivery, which provides continuous drug release and stable plasma concentrations over a period of $24 \mathrm{~h}$ [96]. Clinical studies have shown the efficacy and safety of the rotigotine transdermal patch in the treatment of early and advanced PD [97] and in RLS [98]. An overnight switch from an oral DA to rotigotine patch was effective and well tolerated in clinical studies [99].

The plasma concentration increases within $16 \mathrm{~h}$ after transdermal administration, and falls considerably at 12 hours after patch removal. The mean apparent dose proved to be $61.4 \%$ of the total drug content of the patch. The absolute bioavailability measured for transdermal administration was $37 \%$. In view of the apparent dose of $61.4 \%$ of the dose applied, this means that more than $60 \%$ of the dose absorbed is bioavailable. $T_{1 / 2}$ after removal of the patch was $5.3 \mathrm{~h}$. The pharmacokinetic parameters for rotigotine intravenous and transdermal administration exhibited a similar $\mathrm{C}_{\max }$ and decreasing profile following the termination of drug delivery [100].

The products of the oxidative metabolism of rotigotine are rapidly conjugated to glucuronides or sulfates, as shown in animal models and humans [101]. The phase 1 metabolites have high affinity for dopamine receptors, but a very low plasma level, whereas the phase 2 conjugates have practically no affinity. After transdermal administration of radiolabeled rotigotine, $66 \%$ was eliminated through the kidney and less through the feces, with a total of $88 \%$ of the radioactive dose recovered within $96 \mathrm{~h} \mathrm{[102].} \mathrm{The} \mathrm{renal} \mathrm{elimination} \mathrm{of} \mathrm{the}$ unchanged compound was below $1 \%$. Under steady-state conditions, the mean unconjugated and the total plasma rotigotine concentrations increased in a dose-proportional manner. The ratio of rotigotine to unconjugated rotigotine was identical at all evaluated doses [99]. The bioavailability of rotigotine can present irregularities due to the unstable absorption caused by an improper placement of the patch or by sweating. Problems of absorption arose due to crystal formation in the patches, and this led to temporary withdrawal of the product from the US market. Rotigotine is generally well tolerated. The most common adverse events are application-site reactions, GI disturbances, somnolence and headache [95].

\section{Non-dopaminergic medication}


A broad variety of non-dopaminergic medicaments have been trialed and used in PD, ranging from vitamin $\mathrm{D}$, coenzyme $\mathrm{Q}$, caffeine, nicotine, through antiepileptics such as safinamide and zonisamide or anticholinergic agents, to cannabinoid receptor antagonists or metabotropic glutamate receptor ligands (Table 4) [103].

Several trials that are still ongoing are investigating the effects of nondopaminergic agents such as adenosine A2A antagonists, a2-adrenergic receptor antagonists, 5-HT1Areceptor agonists and compounds acting on the glutamatergic system, on motor symptoms, motor fluctuations and dyskinesias in PD [104]. Safinamide has MAO-B inhibitor properties and a complex mechanism of action. It might be effective as an add-on treatment to DA for early PD [105]. Adenosine A2A receptor antagonists, studied in several clinical trials, showed effectiveness in improving the motors symptoms during the on period and in reducing the length of the off period, without severe side-effects [106]. A synergistic dopaminergic and glutamatergic dysfunction has been revealed in $\mathrm{PD}$, and targeting of the glutamatergic transmission is therefore a promising approach in PD therapy [107].

The main excitatory amino acid in the brain is glutamate. An enhanced release and a prolonged stimulation of the glutamate receptors cause damage to the postsynaptic neurons. Glutamate-induced excitotoxicity can cause a self-maintained cascade of events, such as free radical generation and $\mathrm{Ca}^{2+}$ overload and is linked with a mitochondrial dysfunction. Glutamate receptors in the CNS are the fast-acting ionotropic receptors (the AMPA, the NMDA and the kainate receptors), coupled with sodium or calcium ion channels and the slow modulatory metabotropic receptors (mGluRs), coupled with G-protein [44]. Enhanced glutamatergic activity in the striatum underlies peak-dose dyskinesia. This increases activity in the D1-mediated direct striato-pallidal pathway, consequently inhibits basal ganglia output and causes dyskinesia. LD use has been shown to be associated with specific changes in the distribution and expression of NMDA receptor subunits. In this respect an association between LID and changes in the distribution of NR2B subunits from a synaptic to an extrasynaptic location has been found, suggesting that LD in PD does not normalize basal ganglia function, but shifts it to a different, still not normal state [65]. Glutamate antagonists might improve PD symptoms, reduce excitotoxicity, exert a neuroprotective effect [108], and might reduce dyskinesia, the latter by reducing the cortico-strial glutamatergic input in the direct pathway neurons. Some of the medication already in use for PD treatment such as anticholinergics and amantadine, have an antiglutamatergic activity. NMDA antagonists, especially those capable of blocking the NR2B subunit showed anti-parkinsonian and antidyskinetic effect in animal models, but not in clinical trials. Accordingly, in a large meta- 
analysis NMDA antagonists significantly reduced severity of dyskinesias as compared to placebo, but had no significant effect on motor function [109]. In this class of compounds, more detailed results of research on kynurenines will be presented.

\section{Kynurenines}

One of the metabolic pathways for tryptophan is the kynurenine pathway (Figure 2). This is responsible for the production of nicotinamide adenine dinucleotide and nicotinamide adenine dinucleotide phosphate. The central compound of this pathway is L-kynurenine (LKYN), which can be metabolized in the brain in two ways, either to kynurenic acid (KYNA) or to 3-hydroxy kynurenine (3-OH-L-KYN) and quinolinic acid (QUIN). These metabolites have neuroactive properties, as shown in experimental studies [110-114].

The key enzyme of the kynurenine pathway, kynurenine aminotransferase II (KATII) transforms L-KYN to KYNA through an irreversible transamination. The reduction of KATII activity caused a depletion of KYNA in animal models. KYNA is an NMDA receptor antagonist, a kainate/AMPA receptor antagonist and an inhibitor of the presynaptic $\alpha 7$ nicotinic acetylcholine receptors and has shown neuroprotective properties in animal models.

In contrast, 3-OH-L-KYN and QUIN exert neurotoxic properties. QUIN is localized to glia and immune cells. It is a specific competitive agonist of NMDA receptors presenting the NR2A and NR2B subunits. Through activation of these receptors, QUIN causes the release and inhibits the uptake of endogenous glutamate, and induces lipid peroxidation and production of reactive oxygen species. The result is excitotoxicity, an axon-sparing neuronal loss, and damage to the striato-pallidal encephalinergic neurons. 3-OH-L-KYN causes free radical production. The neurotoxic effect is due in part to a metabolite, 3-hydroxyanthranilic acid.

In patients with $\mathrm{PD}$, there is evidence of an alteration of the kynurenine pathway. It has also been shown that the neuroprotective intermediates are reduced in some brain regions and in the serum, whereas the levels of 3-OH-L-KYN and QUIN are elevated and the level of KAT is reduced. An altered KYNA metabolism in PD is indicated by the measurement of metabolites in the red blood cells and plasma of patients [115]. The result of an altered kynurenine metabolism is over-excitation of the glutamate receptors, with consecutive cell damage therefore an intervention in the kynureninne pathway may have a neuroprotective effect and may alleviate LID [116-118]. 


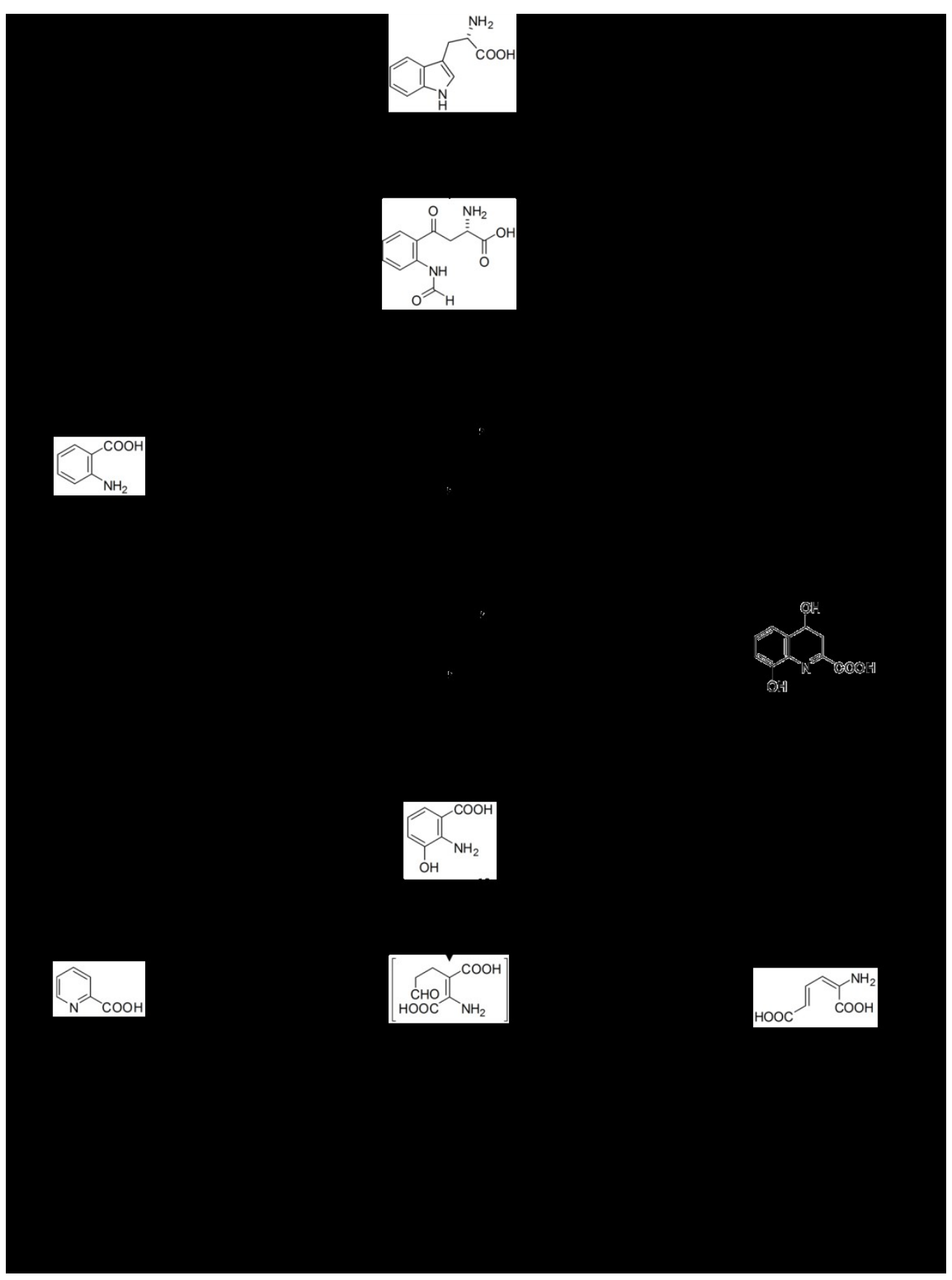

Figure 2. Kynurenine pathway

AADC aromatic amino acid decarboxylase

AUC

area-under-curve

$\mathrm{BBB}$

blood-brain barrier

CD

carbidopa

CDD

continuous dopaminergic delivery

CDS

continuous dopaminergic stimulations

$\mathrm{C}_{\max }$

plasma peak concentration 
COMT

CYP450

DA

DOPAC

ELLDOPA

ER

FIRST STEP
catechol-O methyl transferase

cytochrome P450

dopamine agonists

3-4-dihydroxy-phenylacetic acid

Earlier vs Later L-Dopa

extended release

Favorability of Immediate-Release carbidopa/levodopa vs STalevo,
GI

HP

HVA

IR

KAT

KYNA

LCIG

LD

LID

L-KYN

MAOB

ODT

3-OH-L-KYN

PEG

PEJ

PD

PRESTO

QUIN

REM

RLS

SIBO

SN

SNRI

SSRI

STRIDE-PD

$\mathrm{T}_{1 / 2}$ gastrointestinal

Helicobacter pylori

3-methoxy-4-hydroxy-phenylacetic acid (homovanillic acid)

immediate release

kynurenine aminotransferase

kynurenic acid

levodopa-carbidopa intra-intestinal gel

levodopa

levodopa induced dyskinesia

L-kynurenine

monoamine oxydase B

orally disintegrating tablet

3-hydroxy kynurenine

percutaneous endoscopic gastrostomy

percutaneous endoscopic jejunostomy

Parkinson disease

Parkinson's Rasagiline: Efficacy and Safety in the Treatment of "OFF"

quinolinic acid

rapid eye movement

restless legs syndrome

small intestinal bacterial overgrowth

substantia nigra

serotonine noradrenaline reuptake inhibitor

selective serotonine reuptake inhibitor

STalevo Reduction in Dyskinesia Evaluation

plasma half-life 
TEMPO

TVP-1012 (an early name for rasagiline) in Early Monotherapy for

Parkinson's Disease Outpatients

UPDRS

unified Parkinson's disease rating scale

\section{Conclusions}

The gold standard of PD therapy is levodopa. The characteristics of its pharmacokinetics are a short $\mathrm{T}_{1 / 2}$, absorption through active transport in the small intestine and at the $\mathrm{BBB}$, an extensive peripheral metabolism and renal elimination of the metabolites. There are a number of factors that influence the absorption of levodopa, and thereby cause irregularities in its therapeutic effect, such as DGE, or the competition for the absorption sites in the small bowel. ER formulations and LCIG therapy provide a more stable plasma level. As compared with levodopa, DAs have a longer $\mathrm{T}_{1 / 2}$ and a more stable pharmacokinetic profile. Attention is focused on the development of non-dopaminergic medication and on the development of neuroprotective agents, among which, neuroactive kynurenines have been studied for their antiglutamatergic properties.

\section{Expert opinion}

Levodopa is practically unavoidable in the advanced stages of the disease. A good pharmacokinetic profile is of even more important in these stages of the disease, when the fluctuating plasma levodopa levels can not be buffered by the decreasing number of functional dopaminergic neurons. This is when dopaminergic stimulation becomes dependent on the plasma levodopa level. The CDS concept postulates that a short $\mathrm{T}_{1 / 2}$ is one of the major factors contributing to pulsatile dopamine receptor stimulation and the development of dyskinesias.

Some of the motor fluctuations that are observed in the more advanced stages of the disease are at least partly explained by the irregular ADMET properties of the drug. Motor fluctuations such as delayed-on, no-on and unpredictable off phenomena are explained by bioavailability alterations due to GI involvement in the later stages of the disease.

SIBO and HP infection are common problems among advanced PD patients, contributing to diminished levodopa absorption and to worsening of the (unpredictable) motor fluctuations. Little can be done with these problems for a patient on oral therapy. Certain dietary changes can improve absorption. Infection with HP and SIBO are treatable conditions 
that should be taken into account in the management of advanced-stage patient exhibiting a poor therapeutic response.

Levodopa dosing should be carefully divided throughout the day, and patients should receive advice as concerns medication intake and a proper diet, such as a low-protein intake when taking levodopa and high-fiber diet to improve constipation.

Other dopaminergic agents that influence levodopa breakdown can be co-administered in order to minimize the peripheral side-effects or to reduce MCs. These include COMT and MAO-B inhibitors, which should be chosen on an individual patient basis with regard to pharmacokinetic profile, age and possible side-effects.

It is mandatory to provide the best possible individualized levodopa therapy for each patient, with attention to ensuring optimal absorption, providing smooth, continuous stimulation of the dopaminergic neurons, avoiding especially high plasma levels, considered to be a high risk for the development of dyskinesia. In order to accomplish this, a good knowledge of the pharmacokinetics of the medication used, the possible interactions and the side-effect profile is essential.

Among DAs apomorphine pump, transdermal rotigotine and ER formulations are approaches through which to provide a more constant stimulation of the dopamine receptors, but have limitations due to their side-effect profile.

In the last few years, there have been no substantial changes in the field of dopaminergic agents, but there is now a better understanding of their mechanism of action and of the dopamine metabolism, and the current aspects and targets have been outlined with a view to improving symptomatic control, and minimizing side-effects. The CDS hypothesis stipulates that medication with a longer $\mathrm{T}_{1 / 2}$, which ensures smooth absorption, a less fluctuating plasma level and transport through the BBB, could achieve non-pulsatile stimulation of the dopamine receptors and minimize the long-term side-effect of levodopa therapy, whereas the CDD concept postulates that continuous delivery is the mainstay of the therapy. With regard to the CDD concept, in order to improve delivery, enhance bioavailability and reduce plasma level fluctuations, ER formulations and an intra-intestinal delivery system have been introduced in clinical practice.

LCIG therapy avoids several of the problems caused by DGE. It provides more continuous absorption and consequently steadier levodopa blood levels, a continuous delivery and hence, presumably, a more continuous stimulation of the striatal neurons. Its use is limited by the need for a surgical procedure and high costs. There are other aspects that must be borne in mind, such as the possibility of polyneuropathy development due to a combined B12/B6 
vitamin deficiency, and the risks of technical problems with the pump, and local infections. There also is the dependency on a caregiver to start the pump in the morning hours, or to deliver an extra dose in an off state, if the patient is unable to initiate it. Difficulty is also caused by the large size of the pump, which is inconvenient for many patients. Continuous transdermal levodopa delivery would be a solution for these inconveniencies.

Attention has lately focused on the non-motor symptoms, which can manifest even in the early stages of the disease and have a great impact on the quality of life of the patients. Non-dopaminergic pathways also play a role in their occurrence. These problems and their treatment could not be discussed in this review, for reasons of space. More attention is focused on the development of non-dopaminergic medication, on alleviation of the very troublesome non-motor symptoms and on the development of putative neuroprotective agents. Among these latter, neuroactive kynurenines have been studied for their glutamate antagonist properties; they have been shown to exert antidyskinetic effects in animal models, and their properties suggest that they could also provide a neuroprotective effect in patients with PD.

\section{Acknowledgement}

This research was supported by the European Union and the State of Hungary co-financed by the European Social Fund in the framework of TÁMOP 4.2.4./2-11-1-2012-0001 [1] „National Excellence Program” and „TÁMOP:-4.2.2.A-11/1KONV-2012-0052"

\section{References}

[1] Lees AJ, Hardy J, Revesz T. Parkinson's disease. Lancet 2009;373:2055-66

[2]* Stocchi F. The hypothesis of the genesis of motor complications and continuous dopaminergic stimulation in the treatment of Parkinson's disease. Parkinsonism Relat D. 2009;15:S9-S15

*This paper and paper [60] give a good insight into the continuous dopaminergic stimulation hypothesis and therapeutic approaches respectively. 
[3] Yeh KC, August TF, Bush DF, et al. Pharmacokinetics and bioavailability of Sinemet CR; a summary of human studies. Neurology 1989;39(Supp12):25-38.

[4] Leon AS, Speigel H. The effect of antacid administration on the absorption and metabolism of levodopa. J Clin Pharmacol 1972;12:263-67

[5] Edwards LL, Quingley EMM, Pfeiffer RF. Gastrointestinal dysfunction in Parkinson's disease: frequency and pathophysiology. Neurology1992;42:726-32.

[6] Djaldetti R, Baron J, Ziv I et al. Gastric emptying in Parkinson's disease: patients with and without response fluctuations. Neurology 1996;46:1051-54

[7] Müller T, Erdmann C, Bremen D, et al. Impact of gastric emptying on levodopa pharmacokinetics in Parkinson disease patients. Clin Neuropharmacol 2006;29:61-67

[8] Gabrielli M, Bonazzi P, Scarpellini E, et al. Prevalence of small intestinal bacterial overgrowth in Parkinson's disease. Mov Disord 2011;26:889-92.

[9] Stocchi F, Ruggieri S, Monge A, et al. Clinical efficacy of single morning doses of different levodopa formulations. Clin Neuropharmacol 1994;17(Suppl 3):S16-20.

[10] Stocchi F, Barbato L, Bramante L, et al. Fluctuating parkinsonism: a pilot study of single afternoon dose of levodopa methyl ester. J Neurol 1996;243:377-80.

[11] Stocchi F, Fabbri L, Vecsei L, et al. Clinical efficacy of a single afternoon dose of effervescent levodopa-carbidopa preparation (CHF 1512) in fluctuating Parkinson disease. Clin Neuropharmacol 2007;30:18-24.

[12] Pierantozzi M, Pietroiusti A, Brusa L, et al. Helicobacter pylori eradication and 1-dopa absorption in patients with PD and motor fluctuations. Neurology. 2006;66:1824-29

[13] Lee WY, Yoon WT, Shin HY, et al. Helicobacter pylori infection and motor fluctuations in patients with Parkinson's disease. Mov Disord. 2008;23:1696-1700. 
[14] * Fasano A, Bove F, Gabrielli M, et al. The role of small intestinal bacterial overgrowth in Parkinson's disease. Mov Disord: published online 9 April 2013, doi: 10.1002/mds.25522 *This paper is of interest for the role of SIBO in PD.

[15] Rahne KE, Tagesson C, Nyholm D. Motor fluctuations and Helicobacter pylori in Parkinson's disease. J Neurol.: published online 4 September 2013, doi: 10.1007/s00415-0137089-96

[16] Gasbarrini A, Lauritano EC, Gabrielli M, et al. Small intestinal bacterial overgrowth: diagnosis and treatment. Dig Dis.2007;25:237-40.

[17]* PoeweW, Antonini A, Zijlmans JCM, et al. Levodopa in the treatment of Parkinson's disease: an old drug still going strong. Clinical Interventions in Aging 2010;5 229-38

*This paper summarizes the evidences regarding the use of LD for PD treatment.

[18] Stocchi F. Optimising levodopa therapy for the management of Parkinson's disease. J Neurol 2005;252(Suppl 4):43-8.

[19] Mitsuoka T, Kaseda Y, Yamashita H, et al. Effects of nicotine chewing gum on UPDRS score and P300 in early-onset parkinsonism. Hiroshima J Med Sci 2002;51:33-39

[20] Huang LZ, Grady SR, Quik M. Nicotine reduces L-DOPA-induced dyskinesias by acting at beta $2 *$ nicotinic receptors. J Pharmacol Exp Ther 2011;338:932-41

[21] Zhang D, Mallela A, Sohn D, et al. Nicotinic receptor agonists reduce L-dopa-induced dyskinesias in a monkey model of Parkinson's disease. J Pharmacol Exp Ther 2013: published online 31 July 2013, doi: 10.1124/jpet.113.207639

[22] Ling H, Petrovic I, Day BL et al. Smoking-induced transient motor deterioration in a levodopa-treated patient with Parkinson's disease. J Neurol 2012;259:2419-23

[23] Villafane G, Cesaro P, Rialland A, et al. Chronic high dose transdermal nicotine in Parkinson's disease: an open trial. Eur J Neurol 2007;14:1313-16. 
[24] Kelton MC, Kahn HJ, Conrath CL, et al. The effects of nicotine on Parkinson's disease. Brain Cogn 2000;43:274-82.

[25] Vieregge A, Sieberer M, Jacobs H, et al. Transdermal nicotine in PD: a randomized, double-blind, placebo-controlled study. Neurology 2001;57:1032-35.

[26] Kyaw WT, Nagai M, Kaneta M, et al. Effect of nicotine on the pharmacokinetics of levodopa. Clin Neuropharm 2013;36:46-51

[27] Murata M, Mizusawa H, Yamanouchi H et al. Chronic levodopa therapy enhances dopa absorption: contribution to wearing-off. J Neural Transm 1996;103:1177-85.

[28] Murata M. Levodopa in the early treatment of Parkinson's disease. Parkinsonism Rel Dis 2009;15(suppl):S17-20

[29] http://www.medmerits.com/index.php/article/levodopa/P1

[30] Nutt JG, Woodward WR, Anderson JL. The effect of carbidopa on the pharmacokinetics of intravenously administered levodopa: the mechanism of action in the treatment of parkinsonism. Ann Neurol 1985;18: 537-43

[31]

http://www.inchem.org/documents/pims/pharm/levedopa.htm\#SubSectionTitle:3.4.4\%20Bioa vailability

[32] Rezak M. Current pharmacotherapeutic options in Parkinson's disease. Dis Mon 2007;53:214-22

[33] Kuoppamäki M, Korpela K, Marttila R et al. Comparison of pharmacokinetic profile of levodopa throughout the day between levodopa/carbidopa/entacapone and levodopa/carbidopa when administered four or five times daily Eur J Clin Pharmacol 2009;65:443-55 
[34]* Hauser RA, Lyons KE, McClain T. Parkinson disease. http://emedicine.medscape.com/article/1831191-overview

*This is a thorough review on PD

[35] Hauser RA, Panisset M, Abbruzzese G, et al. Double-blind trial of levodopa/carbidopa/entacapone versus levodopa/carbidopa in early Parkinson's disease. Mov Disord 2009;24:541-50

[36] www.pdtrials.org/en/clinical research_news/release/pr 1236180097

[37] Haasio K. Toxicology and Safety of COMT inhibitors. Internat Rev Neurobiol 2010;95:163-89

[38]* $\quad$ http://www.mayoclinic.com/health/drug-information/DR600837/DSECTION=side$\underline{\text { effects }}$

This reference and reference [39] include description and side effects of levodopa.

[39]* http://www.drugs.com/monograph/levodopa-carbidopa.html\#r104

[40] http://www.reverseparkinsons.net/blog/side-effects-of-medication/medication-is-there-aconnection-between-melanoma-levodopa-and-pd.html

[41] Antonini A, Abbruzzese G, Barone P, et al. COMT inhibition with tolcapone in the treatment algorithm of patients with Parkinson's disease (PD): relevance for motor and nonmotor features. Neuropsych Did Treatment 2008;4:1-9

[42] Hauser RA, McDermott MP, Messing S. Factors associated with the development of motor fluctuations and dyskinesias in Parkinson's disease. Arch Neurol 2006;63:1756-60

[43] Lokk J. Treatment with levodopa can affect latent vitamin B 12 and folic acid deficiency. Patients with Parkinson disease runt the risk of elevated homocysteine levels. Lakartidningen 2003;100:2674-7. 
[44]** Smith Y, Wichmann T, Factor SA, et al. Parkinson's disease therapeutics: new developments and challenges since the introduction of levodopa. Neuropsychopharmacol Rev 2012;37:213-46

**This paper is a thorough review of the therapies in use for Parkinson's disease and the future targets

[45] Agid Y. Levodopa: is toxicity a myth? Neurology 1998;50:858-63.

[46] Olanow CW, Agid Y, Mizuno Y, et al. Levodopa in the treatment of Parkinson's disease: current controversies. Mov Disord 2004;19:997-1005.

[47] Fahn S, Oakes D, Shoulson I, et al. Levodopa and the progression of Parkinson's disease. N Engl J Med 2004;351:2498-508.

[48] Schapira AH. Molecular and clinical pathways to neuroprotection of dopaminergic drugs in Parkinson disease. Neurology 2009;72:S44-50.

[49] Schapira AH, Agid Y, Barone P, et al. Perspectives on recent advances in the understanding and treatment of Parkinson's disease. Eur J Neurol 2009;16:1090-99.

[50] Sethi KD. The impact of levodopa on quality of life in patients with Parkinson disease. Neurologist 2010;16:76-83.

[51] Jenner P, McCreary AC, Scheller DK. Continuous drug delivery in early- and late-stage Parkinson's disease as a strategy for avoiding dyskinesia induction and expression. J Neural Transm. 2011;118:1691-702

[52] * Piedad JCP, Cavanna AE. Dyskinesias and treatment with pramipexole in patients with Parkinson's disease. Parkinson's disease 2012: doi:10.1155/2012/473769

*This paper is of interest for effects of pramipexole on dyskinesias.

[53] Widnell K. Pathophysiology of motor fluctuations in Parkinson's disease. Mov Disord. 2005;20(Suppl 11):S17-S22. 
[54] Ngwuluka N, Pillay V, Du Toit LC, et al. Levodopa delivery systems: advancements in delivery of the gold standard. Expert Opin Drug Deliv 2010;7:203-24.

[55] Calandrella D, Antonini A. Pulsatile or continuous dopaminomimetic strategies in Parkinson's disease. Parkinsonism Relat Disord. 2012;18(Suppl 1):S120-22

[56] Damier P, Tremblay L, Feger J, et al. Development of dyskinesias induced by treatment for Parkinson's disease: potential role of first exposure to L-DOPA (priming). Revue Neurol $2000 ; 156: 224-35$

[57] Jenner P. Avoidance of dyskinesia: preclinical evidence for continuous dopaminergic stimulation. Neurology 2004;62:S47-55

[58] Pahwa R, Factor SA, Lyons KE, et al.Quality Standards Subcommittee of the American Academy of Neurology. Practice Parameter: treatment of Parkinson disease with motor fluctuations and dyskinesia (an evidence-based review): report of the Quality Standards Subcommittee of the American Academy of Neurology. Neurology 2006;66(7):983-95

[59] Bibbiani F, Costantini LC, Patel R, et al. Continuous dopaminergic stimulation reduces risk of motor complications in parkinsonian primates. Exp. Neurol. 2005;192:73-78

[60]* Wright BA, Waters $\mathrm{CH}$. Continuous dopaminergic delivery to minimize motor complications in Parkinson's disease. Expert Rev Neurother 2013;13:719-729

*This paper and paper [2] give a good insight into the continuous dopaminergic stimulation hypothesis and therapeutic approaches respectively.

[61] Nyholm D, Odin P, Johansson A, et al. Pharmacokinetics of levodopa, carbidopa and 3O-methyldopa following 16-hour jejunal infusion of levodopa-carbidopa intestinal gel in advanced Parkinson's disease patients. AAPS 2012;15: 316-23

[62] Westin J, Nyholm D, Palhagen S, et al. A pharmacokinetic-pharmacodynamic model for duodenal levodopa infusion. Clin Neuropharmacol 2011;34:61-5 
[63] Müller T. Drug therapy in patients with Parkinson's disease. Translational Neurodeg $2012 ; 1: 10$

[64] Antonini A, Tolosa E. Apomorphine and levodopa infusion therapies for advanced Parkinson's disease: selection criteria and patient management. Expert Rev Neurother 2009;9:859-67

[65] Olanow CW, Obeso JA, Stocchi F. Continuous dopamine-receptor treatment of Parkinson's disease: scientific rationale and clinical implications. Lancet Neurol. 2006;5:67787

[66] Klostermann F, Jugel C, Müller T, et al. Malnutritional neuropathy under intestinal levodopa infusion. J Neural Transm 2012;119:369-72.

[67] Müller T, van Laar T, Cornblath DR, et al. Peripheral neuropathy in Parkinson's disease: Levodopa exposure and implications for duodenal delivery. Parkinsonism Relat Disord $2013 ; 19: 501-7$

[68] Fernandez HH, Vanagunas A, Odin P et al. Levodopa-carbidopa intestinal gel in advanced Parkinson's disease open-label study: interim results. Parkinsonism Relat Disord 2013;19:339-45

[69] Brooks DJ. Optimizing levodopa therapy for Parkinson's disease with levodopa/carbidopa/entacapone: Implications from a clinical and patient perspective. Neuropsychiatr Dis Treat. 2008;4:39-47.

[70] Hauser RA. IPX066: a novel carbidopa-levodopa extended-release formulation. Expert Rev Neurother 2012;12:133-40

[71] Hauser RA, Ellenbogen AL, Metman LV, et al. Crossover comparison of IPX066 and a standard levodopa formulation in advanced Parkinson's disease. Mov. Disord. 2011;26:224652 
[72] Hauser RA, Hsu A, Kell S, et al. IPX066 ADVANCE-PD investigators. Extended release carbidopa-levodopa (IPX066) compared with immediate-release carbidopa-levodopa in patients with Parkinson's disease and motor fluctuations: a Phase 3 randomised, double-blind trial. Lancet Neurol 2013;12:346-56

[73] Obeso JA, Olanow W. Continuing efforts to obtain continuous delivery of levodopa. Mov Disord 2011;26:2149-50

[74] Abbruzzese G, Barone P, Bonucelli U, et al. Continuous intestinal infusion of levodopa/carbidopa in advanced Parkinson's disease: efficacy, safety and patient selection. Functional Neurol 2012;27:147-54

[75] Nutt GJ. Continuous dopaminergic stimulation: is it the answer to the motor complications of levodopa? Mov Disord 2007;22:1-9

[76] Knoll J, Ecsery Z, Magyar K, et al. Novel (-)deprenyl-derived selective inhibitors of Btype monoamine oxidase. The relation of structure to their action. Biochem Pharmacol $1978 ; 27: 1739-47$

[77] Kincses ZT, Vecsei L. Pharmacological therapy in Parkinson's disease: focus on neuroprotection. CNS Neurosci Ther 2011;17:345-67

[78] Magyar K, Pálfi M, Tábi T, et al. Pharmacological aspects of deprenyl. Curr Med Chem 2004;11:2017-31

[79] Mahmood I. Clinical Pharmacokinetics and pharmacodynamics of seleginline. An update.Clin Pharmacokinet 1997;33:91-102

[80] Tábi T, Szökő É, Vecsei L, et al. The pharmacokinetic evaluation of selegiline (ODT) for the treatment of Parkinson's disease. Expert Opin Drug Metab Toxicol 2013;9:699-712

[81] Chen JJ, Swope DM, Dashtipour K. Comprehensive review of rasagiline, a secondgeneration monoamine oxidase inhibitor for the treatment of Parkinson's disease. Clin Therap 2007;29:1825-49 
[82] Fowler JS, Volkow ND, Logan J, et al. Slow recovery of human brain MAO B after 1deprenyl (selegiline) withdrawal. Synapse 1994;18:86-93

[83] de Marcaida JA, Schwid SR, White WB, et al for Parkinson Study Group TEMPO and the PRESTO tyramine substudy investigators and coordinators. Effects of tyramine administration in Parkinson's disease patients treated with selective MAO-B inhibitor rasagiline. Mov Disord 2006;21:1716-21

[84] Panisset M, Schwid SR, Ondo W, et al. Safety of concomitant therapy with rasagiline and antidepressants in Parkinson's disease. Mov Disord 2007;223(Suppl 16):S104-5

[85] Minguez-Minguez S, Solis-Garcia del Pozo J, Jordan J. Rasagiline in Parkinson's disease: a review based on meta-analysis of clinical data. Pharmacol Res 2013;74:78-86

[86] Parkinson Study Group. Dopamine transporter brain imaging to assess the effects of pramipexole vs levodopa on Parkinson disease progression. JAMA. 2002;287(13):1653

[87] Wood LD. Clinical review and treatment of select adverse effects of dopamine receptor agonists in Parkinson's disease. Drugs Aging 2010;27:295-310

[88] Parkinson Study Group. Pramipexole vs levodopa as initial treatment of Parkinson's disease: A randomized controlled trial. JAMA 2000;284:1931-38

[89] Brodsky MA, Park BS, Nutt JG. Effects of a dopamine agonist on the pharmacodynamics of levodopa in Parkinson's disease. Arch Neurol 2010;67:27-32

[90] Poewe WH, Rascol O, Quinn N, et al. Efficacy of pramipexole and transdermal rotigotine in advanced Parkinson's disease: a double-blind, double-dummy, randomized controlled trial. Lancet Neurol 2007;6:513-20

[91] Eisenreich W, Sommer B, Hartter S, et al. Pramipexole extended release: a novel treatment option in Parkinson's disease. Parkinson's Disease 2010: published online 19 December 2010, doi:10.4061/2010/612619. 
[92] Antonini A, Calandrella D. Once-daily pramipexole for the treatment of early and advanced idiopathic Parkinson's disease: implications for patients. Neuropsych Dis Treat 2011;7:297-302

[93] Poewe W, Rascol O, Barone P, Hauser RA, Mizuno Y, Haaksma M, et al: Extendedrelease pramipexole in early Parkinson disease: a 33-week randomized controlled trial. Neurology 2011, 77:759-66.

[94] Stacy M, Silver D. Apomorphine for the acute treatment of “off” episodes in Parkinson's disease. Parkinsonism Relat Dis 2007;14:85-92

[95] Jankovic J, Aguilar G. Current approaches to treatment of Parkinson's disease. Neuropsy Dis Treat 2008;4:743-57

[96] Braun M, Cawello W, Poole K, et al. Steady-state pharmacokinetics of rotigotine in patients with early-stage Parkinson's disease. Eur J Neurol 2005;12(Suppl 2):96.

[97] Watts RL, Jankovic J, Waters C et al. Randomized, blind, controlled trial of transdermal rotigotine in early Parkinson disease. Neurology 2007;68:272-76.

[98] Trenkwalder C, Benes H, Poewe W, et al. Efficacy of rotigotine for treatment of moderate-to-severe restless legs syndrome: a randomised, double-blind, placebocontrolled trial. Lancet Neurol 2008;7:595-604.

[99] Kim HJ, Jeon BS, Lee WY, et al. Overnight switch from ropinirole to transdermal rotigotine patch in patients with Parkinson disease. BMC Neurology 2011: published online 10 August 2011, doi:10.1186/1471-2377-11-100, http://www.biomedcentral.com/1471$2377 / 11 / 100$

[100] Cawello W, Braun M, Boekens H. Absorption, disposition, metabolic fate, and elimination of the dopamine agonist rotigotine in man: administration by intravenous infusion or transdermal delivery. Drug Metab Disposition 2009;37:2055-60 
[101] Swart PJ, Oelen WE, Bruins AP, et al. Determination of the dopamine D2 agonist N0923 and its major metabolites in perfused rat livers by HPLC-UVatmospheric pressure ionization mass spectrometry. J Anal Toxicol 1994;18:71-77.

[102] Cawello W, Wolff HM, Meuling WJ, et al. Transdermal administration of radiolabelled [14C]rotigotine by a patch formulation: a mass balance trial. Clin Pharmacokinet 2007;46:851-57

[103] www.clinicaltrials.gov

[104]* Poewe W, Mahlknecht P, Jankovic J. Emerging therapies for Parkinson's disease. Curr Opin Neurol 2012;25:448-59

*This review covers the therapies in use for Parkinson's disease.

[105] Schapira AH, Stocchi F, BorgohainR, et al. Long-term efficacy and safety of safinamide as add-on therapy in early Parkinson's disease. Eur J Neurol 2013;20:271-80

[106] Szabó N, Kincses ZT, Vécsei L. novel therapy in Parkinson's disease: adenosine A(2A) receptor antsagonists. Expert Opin Drug metab Toxicol 2011;7:441-55.

[107] Zádori D, Szalárdy L, Toldi J, et al. Some molecular mechanisms of dopaminergic and glutamatergic dysfunctioning in Parkinson's disease. J Neural Transm 2013;120:673-81

[108] Chase TN, Oh JD. Striatal dopamine- and glutamate-mediated dysregulation in experimental parkinsonism TINS 2000;23:86-91

[109] Elahi B, Sun X, Chen R. Effects of NMDA receptor antagonists on levodopa induced dyskinesia. Meta analysis of controlled clinical trials. Mov. Disord. 2009;24 (Suppl. 1):S263

[110] Vámos E, Párdutz A, Klivenyi $\mathrm{P}$, et al. The role of kynurenines in disorders of the central nervous system: possibilities for neuroprotection. J Neurol Sci 2009;283:21-7

[111] Zádori D, Klivényi $\mathrm{P}$, Vamos $\mathrm{E}$, et al. Kynurenines in chronic neurodegenerative disorders: future therapeutic strategies. J Neural Transm 2009;116:1403-9 
[112] Németh H, Toldi J, Vécsei L. Kynurenines, Parkinson's disease and other neurodegenerative disorders: preclinical and clinical studies. J Neurol Transm 2006;70:285304

[113]** Vécsei L, Szalárdy L, Fülöp F, et al. Kynurenines in the CNS: recent advances and new questions. Nat Rev Drug Discov 2013;12:64-82

**This publication and paper [114] are of particular interest for the mechanism of action of kynurenines and their properties.

[114]** Zádori D, Klivényi P, Toldi J. Kynurenines in Parkinson's disease: therapeutic perspectives. J neural transm 2012;119:275-83.

**This publication and paper [113] are of particular interest for the mechanism of action of kynurenines and their properties.

[115] Hartai Z, Klivényi P, Janaky T, et al. L. Kynurenine metabolism in plasma and in red blood cells in Parkinson's disease. J Neurol Sci 2005;239:31-35

[116] Szabó N, Kincses ZT, Toldi J, et al. Altered tryptophan metabolism in Parkinson's disease: a possible novel therapeutic approach. J Neurol Sci 2011;310:256-60.

[117] Gregoire L, Rassoulpour A, Guidetti P, et al. Prolonged kynurenine 3-hydroxylase inhibition reduces development of levodopa-induced dyskinesias in parkinsonian monkeys. Behav. Brain Res. 2008;186:161-7

[118] Knyihar-Csillik E, Csillik B, Pakaski M et al. Decreased expression of kynurenine aminotransferase-I (KAT-I) in the substantia nigra of mice after 1-methyl-4-phenyl-1,2,3,6tetrahydropyridine (MPTP) treatment. Neuroscience 2004;126:899-914 